\title{
Is the oral cavity relevant in SARS-CoV-2 pandemic?
}

\author{
David Herrera $^{1}$ (D) Jorge Serrano ${ }^{1} \cdot$ Silvia Roldán ${ }^{1} \cdot$ Mariano Sanz $^{1}$
}

Received: 14 May 2020 / Accepted: 11 June 2020 / Published online: 23 June 2020

(C) Springer-Verlag GmbH Germany, part of Springer Nature 2020

\begin{abstract}
Objectives Recent scientific evidences suggest a relevant role of the oral cavity in the transmission and pathogenicity of SARSCoV-2.

Methods A literature search was performed in PubMed, up to April 30, 2020, focusing on SARS-CoV-2, COVID-19, oral cavity, and antimicrobial agents.

Results Oral viral load of SARS-CoV-2 has been associated with the severity of COVID-19, and thus, a reduction in the oral viral load could be associated with a decrease in the severity of the condition. Similarly, a decrease in the oral viral load would diminish the amount of virus expelled and reduce the risk of transmission, since (i) during the first 10 days, the virus mainly accumulates at the nasal, oral, and pharyngeal area; (ii) the number of angiotensin-converting enzyme (ACE2) receptor is greater in the salivary glands as compared with the lungs; and (iii) salivary droplets represent the most relevant transmission route. To reduce the oral viral load, antiseptic agents may be used, although the evidence on its efficacy is indirect and weak.

Conclusions Antiseptic mouth rinses, such as those containing cetylpyridinium chloride or povidone-iodine, may be able to decrease the severity of COVID-19 by reducing oral viral load in infected subjects and decreasing the risk of transmission by limiting viral load in droplets, generated in normal life, or in aerosols, produced during dental procedures. Well-designed clinical and preclinical research must be conducted to support these hypotheses.

Clinical relevance Antiseptic mouth rinses may help in decreasing the severity of COVID-19 and in reducing the risk of transmission.
\end{abstract}

Keywords SARS-CoV-2 COVID-19 · Antiseptic $\cdot$ Oral health $\cdot$ Transmission

\section{COVID-2019 and oral cavity}

Coronavirus 2 of severe acute respiratory syndrome (SARSCoV-2), previously known 2019 novel corona virus (2019$\mathrm{nCoV}$ ), a member of the Coronaviridae family is the responsible agent of the disease referred as 2019 coronavirus disease (COVID-2019). This disease was first identified in Wuhan (China), and from there, it has spread to more than 185 countries, acquiring pandemic characteristics, with more than 2.8 million of confirmed cases and almost 0.2 million of dead, on April 25, 2020 [1].

David Herrera

davidher@ucm.es

1 ETEP (Etiology and Therapy of Periodontal and Peri-implant Diseases) Research Group, University Complutense of Madrid, Madrid, Spain
Most patients with COVID-19 present a mild disease, with fever, myalgia or fatigue, and dry cough as main symptoms [2]. However, almost $14 \%$ present signs and symptoms of a severe disease, requiring hospitalization and oxygen support, and 5\% need to be admitted to intensive care units [3]. These severe cases usually include impairment of the function of different organs such as acute kidney injury, cardiac injury, and liver dysfunction and grave complications as severe acute respiratory syndrome (SARS), sepsis, and septic shock [4]. The risk factors associated with this severe systemic impact of COVID-19 in a small proportion of patients infected with SARS-CoV-2 have not been properly identified, although it has been suggested that the presence of other comorbidities, such hypertension, diabetes, coronary disease, aging, and obesity may play a significant role [5].

The role of the oral cavity, as the entrance to the body of SARS-CoV-2, and its possible role as protective/aggravating factor in the infectivity and in the progression of this viral infection have been controversial, although recent scientific evidences suggest a relevant role of the oral cavity and its 
mucosae in the transmission and pathogenicity of SARSCoV-2. In addition, the demonstrated chronic systemic inflammation associated with periodontitis may presuppose a higher risk of increased severity of COVID-19 in periodontitis patients. This predicate is supported by the available scientific evidence supporting the relevance of oral health, and specifically, of periodontal health, on systemic health $[6,7]$ and, again, emphasizing the importance of oral health in the overall systemic health $[8,9]$.

It was, therefore, the objective of the present short communication to evaluate the importance of the oral cavity and the possible impact of using oral antiseptics to reduce the transmission and pathogenicity of SARS-CoV-2.

\section{Methods}

A literature search was performed in PubMed, up to April 30, 2020, focusing on SARS-CoV-2, COVID-19, oral cavity, and antimicrobial agents.

\section{Is the oral cavity relevant in the transmission and pathogenicity of SARS-CoV-2?}

The infectivity of SARS-CoV-2 depends on the ability of this virus to enter the cells, and there is clear evidence that the transmembrane protein angiotensin-converting enzyme (ACE2) is the primary receptor and portal of entrance of this virus into the cell. Besides the lungs, intestines, heart, and kidneys, which have shown expression of ACE2, recent evidence has also demonstrated that epithelial cells in different oral cavity mucosae, especially in the tongue mucosa, show a high expression of ACE2. Since the oral cavity is one of the first interfaces between the exterior and body, there is a high potentiality that this pathway of viral colonization and infection is critical for the onset of COVID-19 [10,11].

Apparently, in the first 10 days after the transmission, when the patient usually remains asymptomatic but is highly contagious, the virus accumulates at the nasal, oral, and pharyngeal mucosa, and only later will further accumulate in the lungs [12]. It has also been shown that the number of ACE2 receptors in the salivary glands is higher than in the lungs that has been suggested could be a reservoir area for SARS-CoV-2 in asymptomatic patients [11].

Two major routes of transmission have been described, on through Flügge droplets ( $>5 \mu \mathrm{m}$ in size), expelled when breathing, talking, sneezing, coughing, etc., which normally will not remain in the air but immediately settle down on different surfaces or on the floor and, from there, indirectly, the virus may be transmitted through contract by the hand or contaminated objects if they contact the subject mucosae. In the other route, viruses will be transmitted directly person to person, via Wells droplet nuclei $(\leq 5 \mu \mathrm{m})$, expelled by breathing, talking, sneezing, coughing, etc., since they remain suspended in air for significant periods of time, allowing them to be transmitted over distances $>1 \mathrm{~m}[11,13]$.

This possible role of the oral cavity both as portal of entrance of the virus in the body and as virus reservoir may be impacted at two levels:

- By decreasing the viral load SARS-CoV-2 that has been associated with a reduced severity of COVID-19 [14].

- By decreasing the viral load, the amount of virus expelled by the carrier could be temporarily reduced and, therefore, the risk of transmission will be lesser. This is supported by different reasons: (i) during the first 10 days, the virus mainly accumulates at the nasal, oral, and pharyngeal area [12]; (ii) the number of ACE2 receptor is greater in the salivary glands as compared with the lungs [11]; and (iii) salivary droplets represent the most relevant transmission route $[11,13]$.

This proposed beneficial impact could become even more relevant under the light of the foreseen evolution of the pandemic, which suggest that in spite of the implementation of hygienic measures and social distance, SARS-CoV-2 may not be eradicated up to 2024 [15]. This positive impact may specifically be even more relevant in the context of the clinical practice of dentistry [16], since due to the frequent generation of aerosols, the associated risk of virus transmission may be enhanced during the different dental procedures $[11,17]$.

\section{Could oral antiseptics have an impact on the transmission and pathogenicity of SARS-CoV-2?}

Some oral antiseptics, used as a pre-procedure rinsing, have shown efficacy to reduce the amount of bacteria in aerosols, hence significantly reducing the risk of cross-infection. This outcome has been demonstrated when rinsing with chlorhexidine before dental procedures [18-20]. Similar outcomes, albeit in lesser extent, have also been demonstrated with the use of essential oil mouth rinses [21]. A recent systematic review, with meta-analysis that evaluated the efficacy of preoperative mouth rinses in the reduction of the number of microorganisms produced by aerosols during dental procedures, concluded that mouth rinses containing chlorhexidine and cetylpyridinium chloride, among others, were efficacious to reduce the bacterial load in the aerosols [22]. There is, however, no direct evidence of the possible impact of preoperative rinsing with oral antiseptics on the SARS-CoV-2 viral load. Furthermore, the likely impact of a daily use of these antiseptics for limited periods of time (e.g., when being a carrier of the virus) on the viral transmissivity has not been explored. However, the possible beneficial effect of using oral 
antiseptics during this viral infection may be assessed indirectly by evaluating the in vitro antiviral activity of most common active agents.

\section{Povidone-iodine}

Pre-procedural rinsing with povidone-iodine has been frequently recommended in protocols specifically applied for dental settings in the control of SARS-CoV-2 [16]. However, it has very limited substantivity in oral use [23], and its use may present some risks, including allergic reactions or thyroid dysfunction in long-term use [24]. The recommendation of mouth rinse/gargling with povidone-iodine in the COVID-19 context is based on its virucidal activity, shown against both enveloped and non-enveloped viruses including ebola, Middle East respiratory syndrome (MERS) and SARS coronavirus, influenza, and hand, foot, and mouth disease (HFMD) viruses (Enterovirus 71 and Coxsackievirus A16) [24]. These recommendations have been partially based on a series of German studies from one research group showing that:

- There is virucidal activity of $1 \%$ povidone-iodine (formulation for rinsing) against MERS-CoV, within $15 \mathrm{~s}$ of exposure, shown in an in vitro study [25].

- Better virucidal activity (against murine norovirus) was shown when using $7.5 \%$ povidone-iodine when compared with $4 \%$ chlorhexidine gluconate [26].

- Povidone-iodine (7.5\%), formulated as gargle/mouthwash but diluted 1:30 to a final concentration of $0.23 \%$ for in vitro rapidly inactivated (15 s of exposure) SARS$\mathrm{CoV}$, MERS-CoV, influenza virus A (H1N1), and rotavirus [27].

In another narrative review on the virucidal activity of povidone-iodine [28], different Japanese in vitro studies were evaluated:

- Inactivation of adenovirus, mumps, rotavirus, poliovirus (types 1 and 3), Coxsackievirus, rhinovirus, herpes simplex virus, rubella, measles, influenza, and human immunodeficiency virus (HIV) [29]

- Efficacy against a SARS coronavirus strain, with rapid inactivation of the virus after 2 min of treatment [30, 31]

- Virucidal activity against avian influenza viruses [32]

- Virucidal efficacy, including when use as gargle, against swine influenza viruses [33]

\section{Cetylpyridinium chloride}

N-hexadecyl pyridinium chloride or cetylpyridinium chloride (CPC) is a cationic quaternary ammonium compound soluble in water and in aqueous solutions, non-oxidant or corrosive, and highly cationic at neutral $\mathrm{pH}$. These compounds belonging to the group of tensioactive agents have been frequently used as detergents and antiseptics. As antiseptic, its antibacterial, antiplaque, and antigingivitis properties have been demonstrated in different randomized clinical trials [34], and its efficacy has been summarized in several systematic reviews [35-37].

In vitro studies have shown that it is able to eliminate/ inactivate different strains of influenza virus (AH3N2, A H1N1, B, oseltamivir-resistant A). The antiviral mechanism of action of CPC resides in its ability to disrupt the lipid envelope, hence interfering with the capacity of the virus to enter the cell. Due to this mechanism of action, it has been suggested that CPC may also act against other viruses with envelope, such as respiratory syncytial virus (RSV), parainfluenza virus, and coronavirus [38]. In a preclinical in vivo investigation using mice adapted to an influenza strain (A H1N1), a statistically significant lower mortality and morbidity were shown in the group of mice using the CPC formulation.

In humans, in a pilot double-blinded, placebo-controlled, randomized clinical trial, assessing a CPC-based formulation for inhalation, in the prevention of upper respiratory tract infections (usually associated with influenza virus, RSV, human metapneumovirus (hMPV), rhinovirus, and adenovirus), it was observed that patients in the test group suffered viral infections with less severity and duration, when compared with those included in the placebo group [39].

Most recently, in a high-throughput screening aiming to identify broad-spectrum inhibitors of coronaviruses, CPC was rated as the 9th most relevant, out of 36, against the four viruses tested, which included MERS-CoV [40].

$\mathrm{CPC}$ products are widely available in the market, formulated as only active agent in different concentrations, but also in combination with other active agents, being of special relevance the formulation together with $0.12 \%$ chlorhexidine, which has shown an important microbiological impact as single rinse [41] or with a 2-week use [42], and also at different concentrations [43], such as $0.05 \%$ evaluated for 6 months [44] or as $0.03 \%$ evaluated for 1 year [45].

\section{Chlorhexidine}

Chlorhexidine is a biguanidic antiseptic and disinfectant, with a widely demonstrated antimicrobial activity against bacteria (gram-positive and gram-negative, anaerobic and aerobic), some viruses, and yeast. As antiseptic, its antibacterial, antiplaque, and antigingivitis properties have clearly established, as summarized in systematic reviews [35-37]. In regard to its antiviral activity, although the use of chlorhexidine has been suggested to reduce the viral transmission via aerosols in recent narrative reviews [46, 47], its efficacy is controversial. In a systematic review, it was reported that chlorhexidine rapidly inactivates lipophilic viruses (e.g., herpes simplex virus, HIV, 
influenza virus, cytomegalovirus) but not small nonenveloped viruses (enteroviruses, polio viruses, papilloma viruses) or enveloped human coronavirus [48].

\section{Other products}

Very limited evidence is available for other products that are frequently recommended in cross-contamination preventive protocols in viral infections:

- Hydrogen peroxide [16] is frequently recommended as part of measures of control of COVID-19, despite the limited available evidence, very limited substantivity [49], or limited impact on dental biofilms [50].

- Essential oil mouth rinses, since there are suggestions of their possible benefits in controlling viral contamination, at least for herpes viruses [51]. However, its use has seldomly been suggested in the COVID-19 context.

- Beta-cyclodextrin and citrox [52] have also been suggested as possible candidates for evaluation.

\section{Comparisons of different agents in non-oral scenarios}

Some information can also be extracted from a narrative review, including 22 articles, that evaluated the relative efficacy of different disinfectant products in other settings, such as disinfection of inanimate surfaces (metal, glass, or plastic), in which different human coronaviruses, including SARS$\mathrm{CoV}$ and MERS-CoV, or endemic human coronaviruses $(\mathrm{HCoV})$ can persist for up to 9 days. Effective inactivation of the viruses was observed with $62-71 \%$ ethanol, $0.5 \%$ hydrogen peroxide, or $0.1 \%$ sodium hypochlorite within $1 \mathrm{~min}$. Other biocidal agents, such as $0.05-0.2 \%$ benzalkonium chloride or $0.02 \%$ chlorhexidine digluconate, were considered as less effective [53].

More recently, and specifically in relation with SARS$\mathrm{CoV}-2$, the in vitro virucidal effect was considered similar with ethanol (70\%), povidone-iodine (7.5\%), chloroxylenol $(0.05 \%)$, chlorhexidine $(0.05 \%)$, or benzalkonium chloride $(0.1 \%)$, when used as disinfectants [54].

\section{Summary}

The recommendations of different health authorities in different countries of the world are indicating the need to perform pre-procedure rinsing with antiseptic agents in dental clinical settings, both during and after the pandemic period. The most frequently recommended agents are povidone-iodine, hydrogen peroxide, and cetylpyridinium chloride, although the scientific support behind these recommendations is still weak and mostly derived from indirect evidence.
The information presented in this narrative review supports the use of antiseptic mouth rinses, both as a single preprocedural use and as daily use during a limited period of time, to impact the transmission and/or pathogenicity of SARSCoV-2, since they have shown to reduce the oral viral load and, therefore, they may reduce the severity of the disease in an infected subject and may reduce the risk of transmission, by reducing the viral load in aerosols, expelled during dental procedures, or in droplets generated when breathing, talking, sneezing, coughing, etc. However, these recommendations must be validated with well-designed clinical trials that evaluate their efficacy.

Authors' contributions All authors participated in the search, selection of relevant articles, analysis of the evidences provided, and preparation of the manuscript.

Funding information The present work was prepared as part of the activities of the Extraordinary Chair Dentaid in Periodontal Research (Cátedra Extraordinaria Dentaid en Investigación Periodontal), University Complutense of Madrid, Spain.

\section{Compliance with ethical standards}

Conflict of interest The authors declare that they have no conflict of interest.

Ethical approval This article does not contain any studies with human participants or animals performed by any of the authors.

Informed consent For this type of study, formal consent is not required.

\section{References}

1. World Health Organization (2020) Coronavirus disease 2019 (COVID-19) situation report - 99

2. Huang C, Wang Y, Li X, Ren L, Zhao J, Hu Y, Zhang L, Fan G, Xu J, Gu X, Cheng Z, Yu T, Xia J, Wei Y, Wu W, Xie X, Yin W, Li H, Liu M, Xiao Y, Gao H, Guo L, Xie J, Wang G, Jiang R, Gao Z, Jin Q, Wang J, Cao B (2020) Clinical features of patients infected with 2019 novel coronavirus in Wuhan, China. Lancet 395(10223):497506. https://doi.org/10.1016/S0140-6736(20)30183-5

3. Novel Coronavirus Pneumonia Emergency Response Epidemiology Team (2020) The epidemiological characteristics of an outbreak of 2019 novel coronavirus diseases (COVID-19) in China. Zhonghua Liu Xing Bing Xue Za Zhi 41(2):145-151. https://doi.org/10.3760/cma.j.issn.0254-6450.2020.02.003

4. Yang X, Yu Y, Xu J, Shu H, Xia J, Liu H, Wu Y, Zhang L, Yu Z, Fang M, Yu T, Wang Y, Pan S, Zou X, Yuan S, Shang Y (2020) Clinical course and outcomes of critically ill patients with SARSCoV-2 pneumonia in Wuhan, China: a single-centered, retrospective, observational study. Lancet Respir Med 8:475-481. https:// doi.org/10.1016/S2213-2600(20)30079-5

5. Wu C, Chen X, Cai Y, Xia J, Zhou X, Xu S, Huang H, Zhang L, Zhou X, Du C, Zhang Y, Song J, Wang S, Chao Y, Yang Z, Xu J, Zhou X, Chen D, Xiong W, Xu L, Zhou F, Jiang J, Bai C, Zheng J, Song Y (2020) Risk factors associated with acute respiratory distress syndrome and death in patients with coronavirus disease 2019 
pneumonia in Wuhan, China. JAMA Intern Med. https://doi.org/ 10.1001/jamainternmed.2020.0994

6. Sanz M, Ceriello A, Buysschaert M, Chapple I, Demmer RT, Graziani F, Herrera D, Jepsen S, Lione L, Madianos P, Mathur M, Montanya E, Shapira L, Tonetti M, Vegh D (2018) Scientific evidence on the links between periodontal diseases and diabetes: consensus report and guidelines of the joint workshop on periodontal diseases and diabetes by the International Diabetes Federation and the European Federation of Periodontology. J Clin Periodontol 45(2):138-149. https://doi.org/10.1111/jcpe. 12808

7. Sanz M, Marco del Castillo A, Jepsen S, Gonzalez-Juanatey JR, D'Aiuto F, Bouchard P, Chapple I, Dietrich T, Gotsman I, Graziani F, Herrera D, Loos B, Madianos P, Michel J-B, Perel P, Pieske B, Shapira L, Shechter M, Tonetti M, Vlachopoulos C, Wimmer G (2019) Periodontitis and cardiovascular diseases: consensus report. $\mathrm{J}$ Clin Periodontol In press

8. Tonetti MS, Jepsen S, Jin L, Otomo-Corgel J (2017) Impact of the global burden of periodontal diseases on health, nutrition and wellbeing of mankind: a call for global action. J Clin Periodontol 44(5):456-462. https://doi.org/10.1111/jcpe.12732

9. Herrera D, Sanz M, Herrera Pombo JL, Gomez Doblas JJ, Guerrero A (2016) Oral health also matters. Semergen 42(4):213-215. https://doi.org/10.1016/j.semerg.2016.04.009

10. Xu H, Zhong L, Deng J, Peng J, Dan H, Zeng X, Li T, Chen Q (2020) High expression of ACE2 receptor of 2019-nCoV on the epithelial cells of oral mucosa. Int J Oral Sci 12(1):8. https://doi.org/ 10.1038/s41368-020-0074-X

11. Xu J, Li Y, Gan F, Du Y, Yao Y (2020) Salivary glands: potential reservoirs for COVID-19 asymptomatic infection. J Dent Res: 22034520918518. https://doi.org/10.1177/0022034520918518

12. Wolfel R, Corman VM, Guggemos W, Seilmaier M, Zange S, Muller MA, Niemeyer D, Jones TC, Vollmar P, Rothe C, Hoelscher M, Bleicker T, Brunink S, Schneider J, Ehmann R, Zwirglmaier K, Drosten C, Wendtner C (2020) Virological assessment of hospitalized patients with COVID-2019. Nature 581:465469. https://doi.org/10.1038/s41586-020-2196-x

13. Xu R, Cui B, Duan X, Zhang P, Zhou X, Yuan Q (2020) Saliva: potential diagnostic value and transmission of 2019-nCoV. Int J Oral Sci 12(1):11. https://doi.org/10.1038/s41368-020-0080-z

14. Liu Y, Yan LM, Wan L, Xiang TX, Le A, Liu JM, Peiris M, Poon LLM, Zhang W (2020) Viral dynamics in mild and severe cases of COVID-19. Lancet Infect Dis 20:656-657. https://doi.org/10.1016/ S1473-3099(20)30232-2

15. Kissler SM, Tedijanto C, Goldstein E, Grad YH, Lipsitch M (2020) Projecting the transmission dynamics of SARS-CoV-2 through the postpandemic period. Science 368:860-868. https://doi.org/10. 1126/science.abb5793

16. Ren YF, Rasubala L, Malmstrom H, Eliav E (2020) Dental care and oral health under the clouds of COVID-19. JDR Clin Trans Res: 2380084420924385. https://doi.org/10.1177/2380084420924385

17. Peng X, Xu X, Li Y, Cheng L, Zhou X, Ren B (2020) Transmission routes of 2019-nCoV and controls in dental practice. Int J Oral Sci 12(1):9. https://doi.org/10.1038/s41368-020-0075-9

18. Logothetis DD, Martinez-Welles JM (1995) Reducing bacterial aerosol contamination with a chlorhexidine gluconate pre-rinse. J Am Dent Assoc 126(12):1634-1639

19. Stirrups DR (1987) Methods of reducing bacterial contamination of the atmosphere arising from use of an air-polisher. Br Dent $\mathrm{J}$ 163(7):215-216

20. Worrall SF, Knibbs PJ, Glenwright HD (1987) Methods of reducing bacterial contamination of the atmosphere arising from use of an air-polisher. Br Dent J 163(4):118-119

21. Fine DH, Yip J, Furgang D, Barnett ML, Olshan AM, Vincent JW (1993) Reducing bacteria in dental aerosols: procedural use of an antiseptic mouthrinse. J Am Dent Assoc 124(10):16-18
22. Marui VC, Souto MLS, Rovai ES, Romito GA, Chambrone L, Pannuti CM (2019) Efficacy of preprocedural mouthrinses in the reduction of microorganisms in aerosol: a systematic review. J Am Dent Assoc 150(12):1015-1026 e1011. https://doi.org/10.1016/j. adaj.2019.06.024

23. Addy M, Wright R (1978) Comparison of the in vivo and in vitro antibacterial properties of providone iodine and chlorhexidine gluconate mouthrinses. J Clin Periodontol 5(3):198-205. https://doi. org/10.1111/j.1600-051x.1978.tb02280.x

24. Eggers M (2019) Infectious disease management and control with povidone iodine. Infect Dis Ther 8(4):581-593. https://doi.org/10. 1007/s40121-019-00260-x

25. Eggers M, Eickmann M, Zorn J (2015) Rapid and effective virucidal activity of povidone-iodine products against Middle East respiratory syndrome coronavirus (MERS-CoV) and modified vaccinia virus Ankara (MVA). Infect Dis Ther 4(4):491-501. https:// doi.org/10.1007/s40121-015-0091-9

26. Eggers M, Koburger-Janssen T, Ward LS, Newby C, Muller S (2018) Bactericidal and virucidal activity of povidone-iodine and chlorhexidine gluconate cleansers in an in vivo hand hygiene clinical simulation study. Infect Dis Ther 7(2):235-247. https://doi.org/ 10.1007/s40121-018-0202-5

27. Eggers M, Koburger-Janssen T, Eickmann M, Zorn J (2018) In vitro bactericidal and virucidal efficacy of povidone-iodine gargle/mouthwash against respiratory and oral tract pathogens. Infect Dis Ther 7(2):249-259. https://doi.org/10.1007/s40121018-0200-7

28. Kanagalingam J, Feliciano R, Hah JH, Labib H, Le TA, Lin JC (2015) Practical use of povidone-iodine antiseptic in the maintenance of oral health and in the prevention and treatment of common oropharyngeal infections. Int J Clin Pract 69(11):1247-1256. https://doi.org/10.1111/ijcp.12707

29. Kawana R, Kitamura T, Nakagomi O, Matsumoto I, Arita M, Yoshihara N, Yanagi K, Yamada A, Morita O, Yoshida Y, Furuya Y, Chiba S (1997) Inactivation of human viruses by povidone-iodine in comparison with other antiseptics. Dermatology 195(Suppl 2):29-35. https://doi.org/10.1159/ 000246027

30. Kariwa H, Fujii N, Takashima I (2006) Inactivation of SARS coronavirus by means of povidone-iodine, physical conditions and chemical reagents. Dermatology 212(Suppl 1):119-123. https:// doi.org/10.1159/000089211

31. Kariwa H, Fujii N, Takashima I (2004) Inactivation of SARS coronavirus by means of povidone-iodine, physical conditions, and chemical reagents. Jpn J Vet Res 52(3):105-112

32. Ito $\mathrm{H}$, Ito $\mathrm{T}$, Hikida $\mathrm{M}$, Yashiro J, Otsuka A, Kida H, Otsuki K (2006) Outbreak of highly pathogenic avian influenza in Japan and anti-influenza virus activity of povidone-iodine products. Dermatology 212(Suppl 1):115-118. https://doi.org/10.1159/ 000089210

33. Ito H, Hikida M, Yashiro J (2009) Virucidal efficacy of povidoneiodine products against swine influenza viruses. Jap J Chemother 57(6):508-510

34. Costa X, Laguna E, Herrera D, Serrano J, Alonso B, Sanz M (2013) Efficacy of a new mouth rinse formulation based on $0.07 \%$ cetylpyridinium chloride in the control of plaque and gingivitis: a 6-month randomized clinical trial. J Clin Periodontol 40(11):10071015. https://doi.org/10.1111/jcpe. 12158

35. Figuero E, Herrera D, Tobias A, Serrano J, Roldan S, Escribano M, Martin C (2019) Efficacy of adjunctive anti-plaque chemical agents in managing gingivitis: a systematic review and network meta-analyses. J Clin Periodontol 46(7):723-739. https://doi.org/10.1111/ jcpe. 13127

36. Escribano M, Figuero E, Martin C, Tobias A, Serrano J, Roldan S, Herrera D (2016) Efficacy of adjunctive anti-plaque chemical agents: a systematic review and network meta-analyses of the 
Turesky modification of the Quigley and Hein plaque index. J Clin Periodontol 43(12):1059-1073. https://doi.org/10.1111/jcpe.12616

37. Serrano J, Escribano M, Roldan S, Martin C, Herrera D (2015) Efficacy of adjunctive anti-plaque chemical agents in managing gingivitis: a systematic review and meta-analysis. J Clin Periodontol 42(Suppl 16):S106-S138. https://doi.org/10.1111/ jcpe. 12331

38. Popkin DL, Zilka S, Dimaano M, Fujioka H, Rackley C, Salata R, Griffith A, Mukherjee PK, Ghannoum MA, Esper F (2017) Cetylpyridinium chloride (CPC) exhibits potent, rapid activity against influenza viruses in vitro and in vivo. Pathog Immun 2(2): 252-269. https://doi.org/10.20411/pai.v2i2.200

39. Mukherjee PK, Esper F, Buchheit K, Arters K, Adkins I, Ghannoum MA, Salata RA (2017) Randomized, double-blind, placebo-controlled clinical trial to assess the safety and effectiveness of a novel dual-action oral topical formulation against upper respiratory infections. BMC Infect Dis 17(1):74. https://doi.org/10. 1186/s12879-016-2177-8

40. Shen L, Niu J, Wang C, Huang B, Wang W, Zhu N, Deng Y, Wang H, Ye F, Cen S, Tan W (2019) High-throughput screening and identification of potent broad-spectrum inhibitors of coronaviruses. J Virol 93(12). https://doi.org/10.1128/JVI.00023-19

41. Herrera D, Roldan S, Santacruz I, Santos S, Masdevall M, Sanz M (2003) Differences in antimicrobial activity of four commercial $0.12 \%$ chlorhexidine mouthrinse formulations: an in vitro contact test and salivary bacterial counts study. J Clin Periodontol 30(4): 307-314. https://doi.org/10.1034/j.1600-051x.2003.00341.x

42. Roldan S, Winkel EG, Herrera D, Sanz M, Van Winkelhoff AJ (2003) The effects of a new mouthrinse containing chlorhexidine, cetylpyridinium chloride and zinc lactate on the microflora of oral halitosis patients: a dual-centre, double-blind placebo-controlled study. J Clin Periodontol 30(5):427-434. https://doi.org/10.1034/j. 1600-051x.2003.20004.x

43. Garcia-Gargallo M, Zurlohe M, Montero E, Alonso B, Serrano J, Sanz M, Herrera D (2017) Evaluation of new chlorhexidine- and cetylpyridinium chloride-based mouthrinse formulations adjunctive to scaling and root planing: pilot study. Int J Dent Hyg 15(4):269 279. https://doi.org/10.1111/idh.12254

44. Escribano M, Herrera D, Morante S, Teughels W, Quirynen M, Sanz M (2010) Efficacy of a low-concentration chlorhexidine mouth rinse in non-compliant periodontitis patients attending a supportive periodontal care programme: a randomized clinical trial. J Clin Periodontol 37(3):266-275. https://doi.org/10.1111/j.1600051X.2009.01521.x

45. Pulcini A, Bollain J, Sanz-Sanchez I, Figuero E, Alonso B, Sanz M, Herrera D (2019) Clinical effects of the adjunctive use of a $0.03 \%$ chlorhexidine and $0.05 \%$ cetylpyridinium chloride mouth rinse in the management of peri-implant diseases: a randomized clinical trial. J Clin Periodontol 46(3):342-353. https://doi.org/10.1111/ jcpe. 13088

46. An N, Yue L, Zhao B (2020) Droplets and aerosols in dental clinics and prevention and control measures of infection. Zhonghua Kou Qiang Yi Xue Za Zhi 55(0):E004. https://doi.org/10.3760/cma.j. cn112144-20200221-00081

47. Su J (2020) Aerosol transmission risk and comprehensive prevention and control strategy in dental treatment. Zhonghua Kou Qiang Yi Xue Za Zhi 55(0):E006. https://doi.org/10.3760/cma.j. cn112144-20200303-00112

48. Karpinski TM, Szkaradkiewicz AK (2015) Chlorhexidinepharmaco-biological activity and application. Eur Rev Med Pharmacol Sci 19(7):1321-1326

49. Lafaurie GI, Zaror C, Diaz-Baez D, Castillo DM, De Avila J, Trujillo TG, Calderon-Mendoza J (2018) Evaluation of substantivity of hypochlorous acid as an antiplaque agent: a randomized controlled trial. Int J Dent Hyg 16(4):527-534. https://doi. org/10.1111/idh.12342

50. Hossainian N, Slot DE, Afennich F, Van der Weijden GA (2011) The effects of hydrogen peroxide mouthwashes on the prevention of plaque and gingival inflammation: a systematic review. Int $\mathrm{J}$ Dent Hyg 9(3):171-181. https://doi.org/10.1111/j.1601-5037. 2010.00492.x

51. Meiller TF, Silva A, Ferreira SM, Jabra-Rizk MA, Kelley JI, DePaola LG (2005) Efficacy of Listerine antiseptic in reducing viral contamination of saliva. J Clin Periodontol 32(4):341-346. https://doi.org/10.1111/j.1600-051X.2005.00673.x

52. Carrouel F, Conte MP, Fisher J, Goncalves LS, Dussart C, Llodra JC, Bourgeois D (2020) COVID-19: a recommendation to examine the effect of mouthrinses with beta-cyclodextrin combined with Citrox in preventing infection and progression. J Clin Med 9(4). https://doi.org/10.3390/jcm9041126

53. Kampf G, Todt D, Pfaender S, Steinmann E (2020) Persistence of coronaviruses on inanimate surfaces and their inactivation with biocidal agents. J Hosp Infect 104(3):246-251. https://doi.org/10. 1016/j.jhin.2020.01.022

54. Chin AWH, Chu JTS, Perera MRA, Hui KPY, Yen H-L, Chan MCW, Peiris M, Poon LLM (2020) Stability of SARS-CoV-2 in different environmental conditions. Lancet Microbe (published online April 2)

Publisher's note Springer Nature remains neutral with regard to jurisdictional claims in published maps and institutional affiliations. 